\title{
Biodegradação de Filmes de PP/PCL em Solo e Solo com Chorume
}

\author{
Adriana de Campos, José C. Marconato, Sandra M. M. Franchetti \\ Departamento de Bioquímica e Microbiologia, UNESP
}

\begin{abstract}
Resumo: Filmes de blenda de poli(ع-caprolactona) (PCL) e polipropileno (PP) foram obtidos por moldagem por compressão. O estudo da biodegradação de filmes de blendas de PP/PCL em solo e solo com chorume foi obtido pela evolução de $\mathrm{CO}_{2}$, perda de massa, ângulo de contato, microscopia eletrônica de varredura (MEV) e calorimetria exploratória diferencial (DSC). As análises de evolução de $\mathrm{CO}_{2}$ mostraram que a biodegradação da blenda de PP/PCL em solo com chorume foi maior que a dos homopolímeros, sugerindo que os polímeros na blenda são mais suscetíveis à degradação, o que se deve à não interação entre PP e PCL. Os resultados também mostraram que os microrganismos do solo com chorume provocaram uma erosão superficial. Verificou-se que a biodegradação do PCL é inibida pelos microrganismos do chorume adicionados no solo.
\end{abstract}

Palavras-chave: Polímeros sintéticos, polímeros biodegradáveis, solo, polipropileno, poli(caprolactona).

\section{Study of Biodegradation of PP/PCL Films in Soil and Soil with Leachate Landfill}

Abstract: Blend films of polycaprolactone (PCL) and polypropylene (PP) have been obtained by melt-pressing of both components. The biodegradation of PP/PCL blend films in soil and soil with leachate landfill has been assessed with measurements of evolution of $\mathrm{CO}_{2}$, weight loss, contact angle, scanning electronic microscopy (SEM) and differential scanning calorimetry (DSC). The respirometric tests showed that the PP/PCL biodegradation in the soil with leachate was higher than the homopolymers, suggesting that the polymers in the blend are more susceptible to biodegradation owing to the lack of interaction between PP and PCL. The results also showed that biodegradation due to microorganisms in the soil with leachate occurred by surface erosion. It was found that the PCL biodegradation is inhibited by the leachate microorganisms added in the soil.

Keywords: Synthetic polymers, biodegradable polymers, soil, polypropylene, poly(caprolactone).

\section{Introdução}

A grande quantidade de resíduos produzidos pela sociedade é um crescente problema ambiental que tem de ser conduzido de forma a alcançar uma sociedade mais sustentável ${ }^{[1]}$. Os resíduos plásticos são derivados principalmente de materiais de embalagem, tais como sacos de lixo, filmes agrícolas, embalagens e recipientes alimentares, que são bastante resistentes ao ataque microbiano. Durante os últimos anos, polímeros biodegradáveis com propriedades físicas e mecânicas adequadas têm recebido atenção especial para substituir polímeros à base de petróleo ${ }^{[2]}$. Dentre eles se destaca a poli(caprolactona) (PCL), um poliéster alifático sintético com propriedades semelhantes a polímeros à base de petróleo e facilmente biodegradável. O PCL é um polímero semicristalino com um ponto de fusão $\left(\mathrm{T}_{\mathrm{m}}\right)$ entre 59 e $64{ }^{\circ} \mathrm{C}$, dependendo do conteúdo cristalino, e uma temperatura de transição vítrea $(\mathrm{Tg})$ em torno de $-60^{\circ} \mathrm{C}^{[3]}$. Devido à sua biocompatibilidade, capacidade de formar blendas e copolímeros compatíveis com uma vasta gama de outros polímeros, tem sido utilizado para melhorar as propriedades mecânicas, processabilidade e permeabilidade dos materiais, expandindo as suas aplicações ${ }^{[3,4]}$. O PCL é importante pela sua grande aplicação industrial e forma sistemas miscíveis com diversos polímeros sintéticos, inclusive com o $\mathrm{PVC}^{[5]}$.

O PP é um termoplástico semicristalino do grupo das poliolefinas, com $\mathrm{Tg}$ de $4-12{ }^{\circ} \mathrm{C}$ e $\mathrm{T}_{\mathrm{m}}$ de $165-175{ }^{\circ} \mathrm{C}$. Possui alta cristalinidade, $60-70 \%$, o que produz um material rígido e resistente ${ }^{[6]}$. É importante a mistura de um polímero sintético com um biodegradável para minimizar o efeito do descarte deste material na natureza. Este trabalho pretende contribuir para o desenvolvimento da área de biodegradação deste tipo de blenda e na redução do custo do PCL Além disso, existem poucos trabalhos de blendas de PP com outros polímeros, sendo que em um deles constatou-se que a separação de fases do polímero favorece a biodegradação $0^{[7]}$.
Blendas de PP/PCL-poli(etileno glicol) (PEG) foram estudadas por Tjong et al. ${ }^{[8]}$, que verificaram a imiscibilidade do sistema, com separação de partículas do copolímero PCL-PEG na matriz de PP. Esses autores utilizaram um compatiblizante (anidrido maleico) para melhorar a miscibilidade da blenda e suas propriedades mecânicas.

O objetivo deste trabalho foi investigar o comportamento dos polímeros PP e PCL na blenda de PP/PCL 1:1, quando em contato com os microrganismos do solo e do chorume, através da evolução de $\mathrm{CO}_{2}$, de perda de massa e de ângulo de contato, DSC e MEV.

\section{Materiais e Métodos}

Os polímeros, utilizados na forma de pó, foram: poli(ع-caprolactona) (PCL da Solvay - K-6800, com massa molar média (Mळ) 85.000 g.mol ${ }^{-1}$, temperatura de transição vítrea $(\mathrm{Tg})-71{ }^{\circ} \mathrm{C}$, temperatura de fusão $\left(\mathrm{T}_{\mathrm{m}}\right) 60{ }^{\circ} \mathrm{C}$, entalpia de fusão $\left(\Delta \mathrm{H}_{\mathrm{m}}\right) 58 \mathrm{~J} . \mathrm{g}^{-1[3]}$ e polipropileno isotático (iPP) da Suzano Petroquímica S.A. (TS6100, com Mळ 145.000 g.mol ${ }^{-1}$,

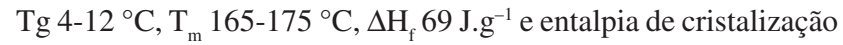
$\left(\Delta \mathrm{H}_{\mathrm{c}}\right) 68,9 \mathrm{~J} \cdot \mathrm{g}^{-1}$.

\section{Preparo dos filmes}

Os filmes de PP, PCL e PP/PCL (1:1 w/w) foram obtidos por moldagem de compressão, utilizando-se pressão hidráulica de $89,10 \mathrm{kgf.cm}{ }^{-1}$, a $180{ }^{\circ} \mathrm{C}$, durante 5 minutos. Os homopolímeros em pó foram pesados ( $0,2 \mathrm{~g}$ no total $)$ e colocados entre películas de teflon, obtendo filmes cerca de $100 \mu \mathrm{m}$ de espessura ${ }^{[7]}$. As blendas foram obtidas a partir de $0,1 \mathrm{~g}$ de cada polímero. 


\section{Preparação do solo}

O solo de jardim foi obtido próximo do Departamento de Bioquímica e Microbiologia da Unesp de Rio Claro, SP e foi peneirado em uma peneira de 2 mesh. A capacidade de campo do solo utilizado nos experimentos foi de $60 \%$, ideal para o crescimento microbiano ${ }^{[9]}$. O solo e o solo com chorume não foram esterilizados, com a finalidade de manter os microrganismos vivos para atuar sobre os filmes poliméricos ${ }^{[10]}$. O chorume foi coletado de aterro sanitário, apresentando um $\mathrm{pH}$ de 7.0 e contendo uma grande diversidade de microrganismos e metais pesados, porém os últimos não foram determinados por análises qualitativas.

O solo foi analisado quimicamente pelo método padrão do IAC (Instituto Agronômico de Campinas) ${ }^{[11]}$. O solo original continha $227 \mathrm{~g} / \mathrm{cm}^{3}$ de matéria orgânica, 39\% de areia, $45 \%$ de silte e $16 \%$ de argila, com pH 5.9, sendo este favorável ao crescimento microbiano ${ }^{[9,12]}$.

\section{Preparo das colunas de solo}

As amostras de filmes, em duplicatas, foram incubadas em colunas de solo (garrafas de PET. transparentes para favorecer a entrada de luz), com altura de $25 \mathrm{~cm}$ e diâmetro de $13 \mathrm{~cm}$ e dois furos na base. Estes furos permitiram a umidificação do sistema por capilaridade, mantendo a média de $48 \%$ de umidade, durante os 120 dias de experimento. Amostras de $8 \mathrm{~cm}$ de diâmetro, foram enterradas no topo da coluna, que continha $17 \mathrm{~cm}$ de solo úmido e cobertura de $2 \mathrm{~cm}$ de terra, para permitir a ação dos microrganismos aeróbios. As colunas tinham aproximadamente 40 furos distribuídos uniformemente, nas suas paredes, para a oxigenação de seu interior. As amostras de filmes foram enterradas nas colunas de solo contendo chorume, nas mesmas condições de trabalho.

Os filmes foram removidos do solo para análise após 30, 45, 60, 90 e 120 dias de tratamento. Após o tratamento microbiano, os filmes foram lavados com água destilada, secos com papel filtro e mantidos por 48 horas em dessecador à vácuo.

\section{Testes respirométricos}

Os filmes de PP, PCL e PP/PCL 1:1, de aproximadamente $100 \mu \mathrm{m}$ de espessura e $0.2 \mathrm{~g}$ em massa, foram enterrados no solo de jardim e no solo com chorume não-estéril, dentro de um respirômetro Bartha (em triplicata) à $28{ }^{\circ} \mathrm{C}$ durante 120 dias, seguindo a norma técnica da NBR 14283 - ABNT ${ }^{[13]}$. Uma descrição detalhada dos testes de biodegradação, utilizando o método respirométrico, é dada por Campos et al. ${ }^{[10]}$.

\section{Caracterização}

\section{Medidas de massa}

Medidas de perda de massa dos filmes foram obtidas em escala analítica após os biotratamentos. A degradação microbiana pode ser expressa como porcentagem de perda de massa (Equação 1) ${ }^{[14]}$ :

$$
\text { Perda de massa }(\%)=\left[\frac{\left(\mathrm{W}_{0}-\mathrm{W}_{1}\right)}{\mathrm{W}_{0}}\right] \times 100 \%
$$

onde $\mathrm{W}_{0}$ e $\mathrm{W}_{1}$ são massas dos filmes antes e após o biotratamento, respectivamente.

\section{Medidas de ângulo de contato}

As amostras de filmes antes e após o biotratamento foram colocadas em lâminas de vidro liso, onde uma gota $(20 \mu \mathrm{m}) \mathrm{de}$ água destilada foi depositada. A gota foi iluminada e sua imagem ampliada e projetada em uma tela branca onde o ângulo de contato foi medido. O procedimento foi repetido 3 vezes e o desvio médio foi calculado a partir destas medições ${ }^{[10]}$.

\section{Calorimetria exploratória de varredura (DSC)}

As curvas e os parâmetros de DSC foram obtidas utilizando amostras de $6 \mathrm{mg}$ de massa, medidas em um calorímetro diferencial (TA Instruments DSC2910), a partir de 25 a $250{ }^{\circ} \mathrm{C}$, com taxa de aquecimento de $10{ }^{\circ} \mathrm{C} / \mathrm{min}$, em uma atmosfera de nitrogênio $50 \mathrm{~mL} / \mathrm{min}$. O calorímetro foi devidamente calibrado utilizando o padrão de Índio $\left(\mathrm{T}_{\mathrm{m}}=159,11^{\circ} \mathrm{C} ; \Delta \mathrm{H}_{\mathrm{m}}=30.66 \mathrm{~J}_{\mathrm{J}} \mathrm{g}^{-1}\right)$.

$\mathrm{O}$ grau de cristalinidade da blenda foi calculado considerando

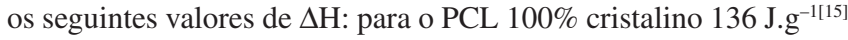
e para iPP $100 \%$ cristalino $\Delta \mathrm{H}_{\mathrm{m}}$ de $190 \mathrm{~J}^{\mathrm{g}} \mathrm{g}^{-1[16]}$.

\section{Microscopia eletrônica de varredura (MEV)}

A morfologia dos filmes foi examinada em um microscópio eletrônico de varredura (MEV) Carl Zeiss DSM 940-A, à $5 \mathrm{kV}$ e $200 \times$ de aumento (ESALQ-USP-Piracicaba). Os filmes originais e após o tratamento microbiano foram recortados e acoplados nos stubs com fita dupla face de carbono e recobertos com ouro, em câmara de vácuo, utilizando o metalizador Bal-Tec SC SCD050, com sputtering.

\section{Resultados e Discussão}

Os filmes de $100 \mu \mathrm{m}$ de espessura apresentaram-se com partes transparentes e partes opacas, em toda sua extensão.

\section{Testes respirométricos}

As análises de evolução de $\mathrm{CO}_{2}$ dos filmes de PCL, PP e blenda PP/PCL são apresentadas na Figura 1.

Verificou-se a tendência da evolução de $\mathrm{CO}_{2}$ acumulativa durante 120 dias, observando-se que o filme de PCL e da blenda de PP/PCL apresentaram evolução de $\mathrm{CO}_{2}$ similar, porém o filme de PP apresentou menor evolução de $\mathrm{CO}_{2}$ quando comparado com o $\mathrm{CO}_{2}$ liberado do solo sem o filme. O homopolímero inibe de certa forma a atividade microbiana do solo, agindo como um controle negativo (efeito modulador ou controlador) da evolução de $\mathrm{CO}_{2}$, tal como o polietileno, citado na norma D-5338-98 ${ }^{[17]}$ (Figura 1a). No caso da adição de chorume, as curvas de evolução de $\mathrm{CO}_{2}$ são muito próximas, devido à variedade da população microbiana adaptada à presença de materiais orgânicos persistentes neste ambiente (Figura 1b).

\section{Medidas de perda de massa}

Filmes de PCL e PP/PCL apresentaram diminuição de massa após o tratamento microbiano. Os filmes de PCL sofreram grande diminuição de massa em 30 e 60 dias de tratamento, chegando a $67 \%$ quando tratados em solo e $89 \%$ quando tratados em solo com chorume (Tabela 1). Observou-se que após 30 dias de tratamento em solo com chorume, os filmes de PCL apresentaram maior perda de massa em relação ao filme tratado somente em solo, sugerindo a adaptação dos microrganismos do chorume em relação ao solo e ao polímero. O filme de PCL com 90 dias de tratamento em solo e solo com chorume estava muito degradado, o que impossibilitou a pesagem e análise do mesmo. A blenda de PP/PCL 1:1 apresentou grande diminuição de massa, após o tratamento microbiano com solo, porém menor quando se adicionou chorume. Estas variações com o passar do tempo, se devem à variação da população microbiana no solo e no solo com chorume.

As perdas de massa dos filmes de PP/PCL em solo e solo com chorume são bem menores que as dos filmes de PCL, a partir de 45 dias, (considerando a correção de massa para o PCL na blenda). Esta diferença de perda de massa sugere que o PP tem efeito modulador sobre o PCL (o PP controla a rápida biodegradação 


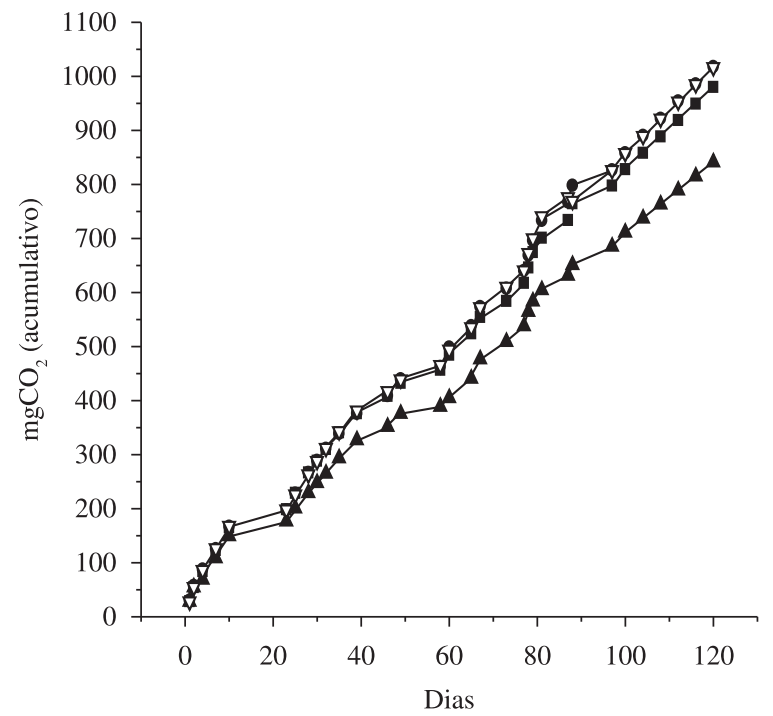

(a)

\begin{tabular}{ll|}
$\rightarrow-$ Solo & $\rightarrow$ PCL + solo \\
$\leftarrow$ PP + solo & $\rightarrow-\mathrm{PP} / \mathrm{PCL}+$ solo
\end{tabular}

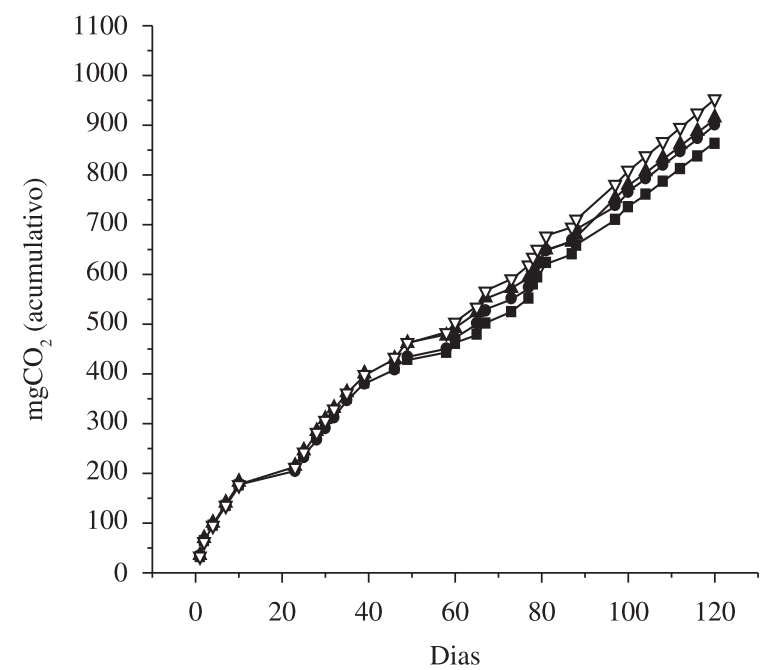

(b)

$\begin{array}{ll}\rightarrow-\text { Solo }+ \text { chorume } & \rightarrow \text { PCL }+ \text { solo + chorume } \\ \leftarrow \text { PP + solo + chorume } & \rightarrow-\text { PP/PCL + solo + chorume }\end{array}$

Figura 1. Produção acumulada de $\mathrm{CO}_{2}$ durante 120 dias de incubação: a) solo; b) solo com chorume.

Tabela 1. Medidas de perda de massa dos filmes de PP, PCL e após o tratamento microbiano.

\begin{tabular}{cccc}
\hline Filmes & $\begin{array}{c}\text { Solo } \\
\text { (\% de perda de massa) }\end{array}$ & $\begin{array}{c}\text { Solo com chorume } \\
(\% \text { de perda de massa })\end{array}$ & $\begin{array}{c}\text { Desvio } \\
\text { padrão }\end{array}$ \\
\hline $\begin{array}{c}\text { PP } \\
120 \text { dias }\end{array}$ & 0 & 0 & - \\
PCL & 24,9 & 15,4 & $\pm 0,6$ \\
30 dias & & & \\
$\quad$ PCL & 53,6 & 70,7 & $\pm 0,8$ \\
45 dias & & & \\
PCL & 66,8 & 88,6 & $\pm 0,5$ \\
60 dias & & & \\
PP/PCL & 48,5 & 33,7 & $\pm 0,5$ \\
120 dias & & & \\
\hline
\end{tabular}

Observação: Considerando a correção de massa na blenda tratada por 120 dias em solo e solo com chorume e ressaltando que todo o PCL havia sido degradado em 120 dias, nos dois casos.

de PCL, inibindo-a). Isto indica que a biodegradação ocorre nas interfases de PP e PCL (nas áreas de contato entre os dois polímeros diferentes, regiões menos ordenadas), tal como visto em Gonçalves et al. ${ }^{[7]}$.

\section{Medidas de ângulo de contato dos filmes tratados em coluna de solo}

As medidas de ângulo de contato dos filmes originais e tratados são apresentadas na Tabela 2. Diminuição do ângulo de contato indica que a superfície polimérica tornou-se mais hidrofílica, devido à ação microbiana (adesão e erosão) ${ }^{[18]}$. Quando há adesão de diferentes materiais orgânicos presentes no meio, a superfície pode se tornar hidrofóbica.

Os filmes de PCL não foram analisados por apresentarem muitos orifícios após os tratamentos microbianos.

O filme de PP apresentou o ângulo de contato semelhante ao do filme original. $\mathrm{O}$ filme tratado em solo com chorume teve aumento no ângulo de contato, mostrando que o mesmo se tornou mais hidrofóbico. O PCL não foi recuperado do solo, degradou
Tabela 2. Medidas de ângulo de contato dos filmes de PP e PP/PCL.

\begin{tabular}{lcccc}
\hline Filmes & Original & solo & $\begin{array}{c}\text { Solo com } \\
\text { chorume }\end{array}$ & $\begin{array}{c}\text { Desvio } \\
\text { padrão }\end{array}$ \\
\hline PP & $57^{\circ}$ & $56,6^{\circ}$ & $67,5^{\circ}$ & $\pm 0,5$ \\
PCL & $60,7^{\circ}$ & - & - & - \\
PP/PCL & $58,7^{\circ}$ & $48^{\circ}$ & $63,7^{\circ}$ & $\pm 0,7$ \\
\hline
\end{tabular}

completamente, não sendo possível efetuar as medidas de ângulo de contato. No caso da blenda tratada em solo, o ângulo de contato diminuiu em relação ao filme original, enquanto que para a blenda tratada em solo com chorume, o ângulo de contato aumentou, tornando o filme mais hidrofóbico

Isto sugere que a biodegradação do PCL na blenda é influenciada pela presença de $\mathrm{PP}$, ocorrendo a biodegradação nas interfases de $\mathrm{PPe}$ PCL. Além disso, existem evidências na literatura ${ }^{[18]}$ que a superfície do PP pode ser colonizada por determinados microrganismos, tais como Pseudomonas e Vibrio sp. ${ }^{[19]}$. Os resultados são difíceis de serem interpretados devido à heterogeneidade da blenda e presença de interfases, bem como do sistema microbiano presente no solo com chorume. Para melhor compreender as mudanças ocorridas nos filmes, foram feitas análises de DSC.

\section{Calorimetria exploratória diferencial (DSC)}

As curvas de DSC são apresentadas nas Figuras 2 a 4 e os parâmetros dos termogramas na Tabela 3 .

O filme de PCL após 30 dias de tratamento microbiano em solo apresentou aumento da temperatura de fusão (Figura 2a) e aumento da cristalinidade (Tabela 3). Estas mudanças indicam reorganização das lamelas e aumento de sua espessura, respectivamente, após a degradação da fase amorfa. Este filme, quando tratado em solo com chorume (Figura 2b), teve sua cristalinidade diminuída, devido à erosão em toda a extensão do filme (fases amorfa e cristalina).

Filmes de PP semicristalino quando tratados em solo e solo com chorume (Figura 3a e b) apresentaram diminuição da cristalinidade (Tabela 3). 


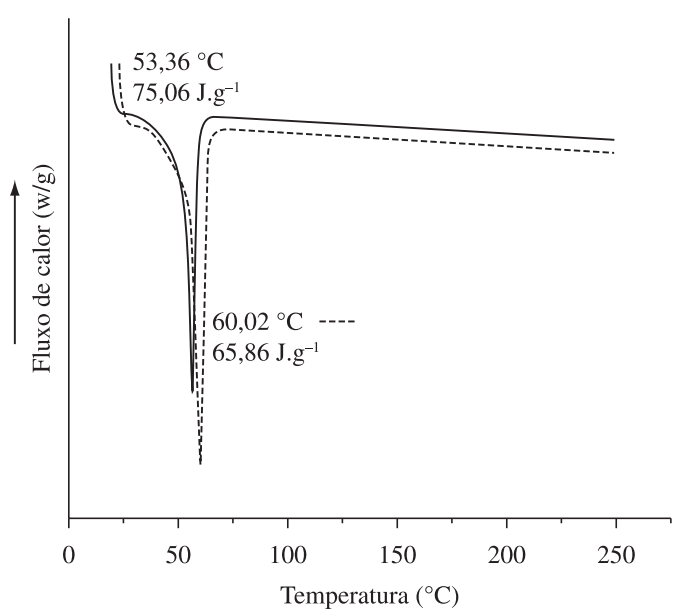

(a)

- PCL original ---- PCL 30 dias solo

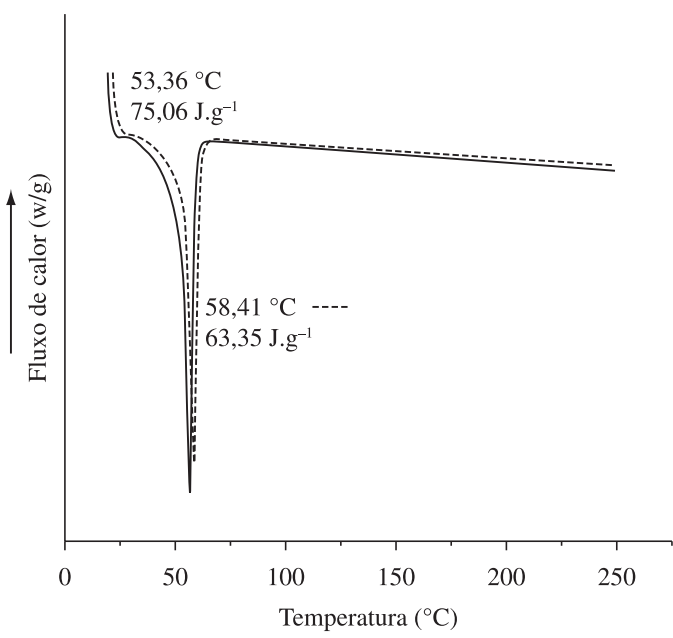

(b)

Figura 2. Curvas de DSC de filmes de PCL original e após 30 dias de tratamento microbiano: a) solo e b) solo + chorume.
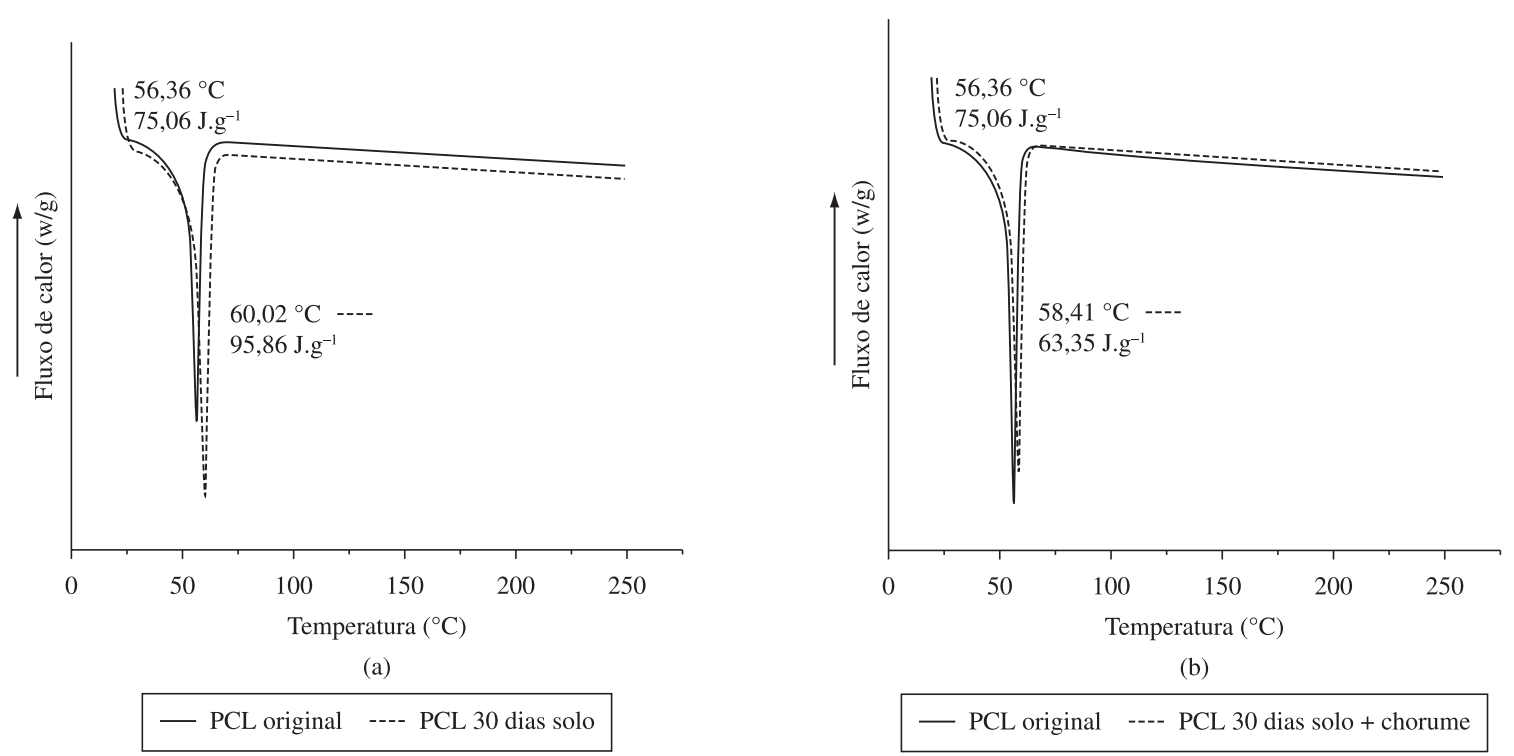

Figura 3. Curvas de DSC de filmes de PP original e após 120 dias de tratamento microbiano: a) solo e b) solo + chorume.

Tabela 3. Parâmetros obtidos dos termogramas das amostras de PCL, PP e PP/PCL 1:1, $\mathrm{T}_{\mathrm{m}}\left({ }^{\circ} \mathrm{C}\right)=$ temperatura de fusão, $\mathrm{X}_{\mathrm{DSC}}=$ porcentagem de cristalinidade obtido por DSC.

\begin{tabular}{lrccl}
\hline \multicolumn{1}{c}{ Amostra } & & $\mathbf{T}_{\mathrm{m}}\left({ }^{\circ} \mathbf{C}\right)$ & $\Delta \mathbf{H}_{\mathrm{m}}\left(\mathbf{J . g}^{-1}\right)$ & $\mathbf{X}_{\mathrm{DSC}}(\%)$ \\
\hline PCL original & & 56,36 & 75,06 & 55 \\
PCL solo & 60,02 & 95,86 & 70,5 \\
PCL solo + chorume & 58,41 & 63,35 & 47 \\
PP original & & 161,60 & 97,99 & 52 \\
PP solo & 161,77 & 88,44 & 46,5 \\
PP solo + chorume & & 162,52 & 89,45 & 47 \\
PP/PCL original & & 59,85 & 35,35 & 37 \\
& & 161,90 & 47,94 & 50,5 \\
PP/PCL solo & (PCL) & 59 & 9,53 & $10(\mathrm{PCL})$ \\
& $(\mathrm{PP})$ & 161,71 & 65,62 & $69(\mathrm{PP})$ \\
PP/PCL solo + chorume & (PCL) & 58,39 & 17,40 & $18(\mathrm{PCL})$ \\
& (PP) & 161,37 & 72,07 & $76(\mathrm{PP})$ \\
\hline
\end{tabular}

Referência: PCL $100 \%$ cristalino, $\Delta \mathrm{H}_{\mathrm{m}}=136 \mathrm{~J}^{-1[1[2]},{ }_{\mathrm{i}} \mathrm{PP} 100 \%$ cristalino, $\Delta \mathrm{H}_{\mathrm{m}}=190 \mathrm{J.g}^{-1[10]}$.
Filmes de PP/PCL 1:1 tratados em solo e solo com chorume (Figura 4a) apresentaram 2 picos de fusão, indicativos de 2 fases na blenda. $\mathrm{O} 1^{\circ}$ pico se refere à fusão do $\mathrm{PCL}$ e o $2^{\circ}$ pico à fusão do $\mathrm{PP}$. Observou-se que os filmes originais de PP tem cristalinidade maior que o PP na blenda PP/PCL. Segundo Chun et al. ${ }^{[20]}$, filmes de PP homopolímero tem cristalização mais acelerada do que na blenda de PP/PCL, o que se deve ao aumento na razão de nucleação e orientação das cadeias. Após os tratamentos, observou-se diminuição da cristalinidade do $1^{\circ}$ pico (PCL) e aumento de cristalinidade no $2^{\circ}$ pico (PP), sugerindo a degradação do PCL inclusive de finais de cadeias, na fase cristalina e reorganização das cadeias do $\mathrm{PP}^{[14]}$. Segundo Gonçalves et al. ${ }^{[7]}$, o aumento de cristalinidade do PP pode ser causado devido a formação de novos cristais na fase amorfa ou a incorporação de moléculas em cristais pré existentes (Figura 4a e b). Essas mudanças ocorrem nas interfases (PP-PCL) da blenda heterogênea e são consideradas como parte do processo biodegradativo. Isto sugere que a heterogeneidade (separação de fase), neste caso, favorece a biodegradação da blenda. 


\section{Microscopia eletrônica de varredura (MEV)}

$\mathrm{O}$ filme de PCL obtido por fusão (Figura 5a) apresentou superfície lisa, com alguns relevos. Os filmes de PCL tratados em solo, durante 30 dias, (Figura 5b) apresentaram orifícios e a presença de estruturas diferenciadas. No tratamento de 45 dias e 60 dias (Figura 5c e d), o filme tornou-se mais deteriorado, com a presença de crateras em toda sua extensão.

Os filmes de PCL tratados em solo com chorume (Figura 5e, fe g) apresentaram grande mudança superficial, com orifícios, decorrentes da erosão da superfície e estruturas diferenciadas, sugerindo adesão microbiana. Os filmes tratados em solo com chorume apresentaram-se semelhantes aos filmes tratados somente em solo.

O PP obtido por fusão (Figura 6a) apresentou relevos em sua superfície. Quando tratado em solo (Figura 6b), e em solo com chorume (Figura 6c), verificou-se um aumento das estruturas em relevo com maior aglomeração das mesmas.

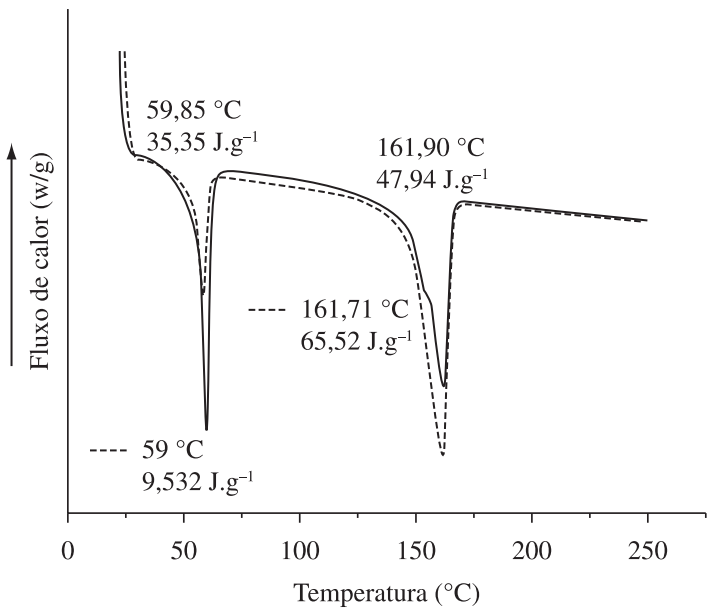

(a)

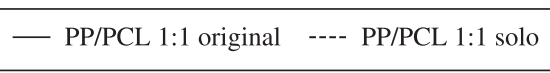

OPPéresistente à decomposição por microrganismos, no entanto, mudanças morfológicas podem ocorrer, mudanças essas causadas por contração das camadas da superfície, como consequiência da quemi-cristalização ${ }^{[7]}$. Essas mudanças morfológicas também podem indicar ataque microbiano na superfície polimérica, assim como observado por Arkatkar et al. ${ }^{[18]}$, que constataram a adesão de Bacillus na superfície de filmes de PP.

As micrografias da blenda apresentadas na Figura 7 mostraram que a microscopia do filme original apresentou estruturas alongadas (Figura 7a), que se modificaram, isto é: sofreram erosão Figura 7b). A erosão se deveu à presença do PCL na blenda, bastante suscetível ao ataque microbiano. A blenda biotratada em solo com chorume (Figura 7c) apresentou a superfície alterada, com estruturas alongadas, diferentes da blenda original. Não ocorreu erosão tão intensa como no caso dos filmes de PCL, sugerindo o efeito inibidor do PP sobre a biodegradação do PCL.

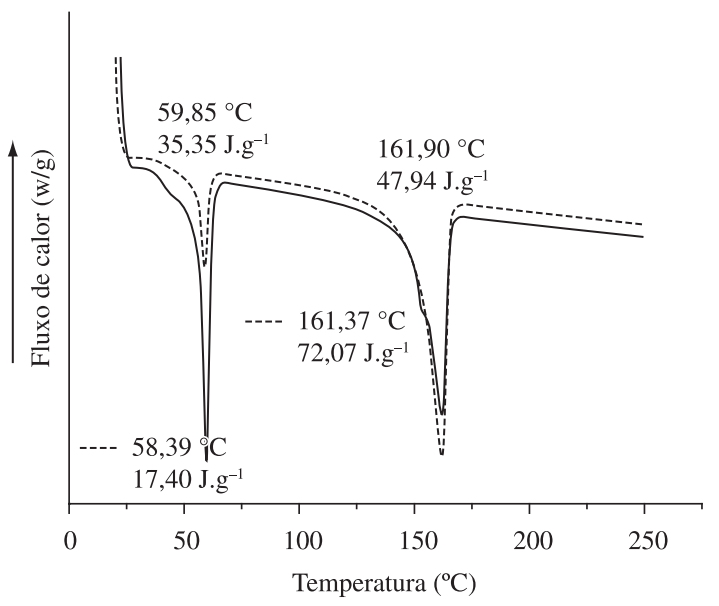

(b)

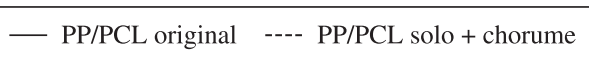

Figura 4. Curvas de DSC de filmes de PP/PCL original e após 120 dias de tratamento microbiano: a) solo e b) solo + chorume.

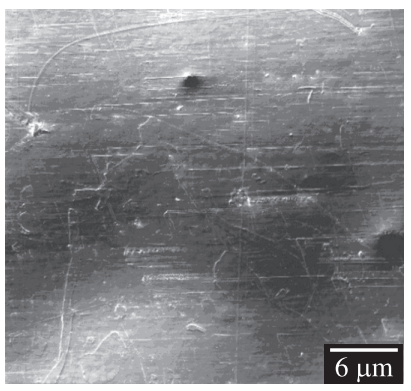

(a)

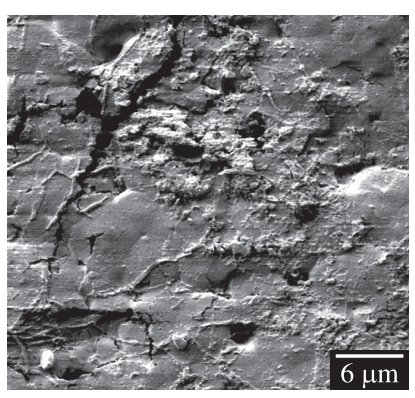

(b)

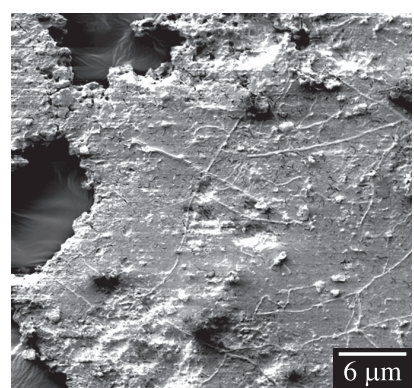

(c)

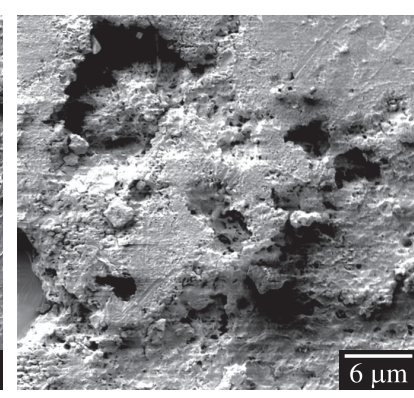

(d)

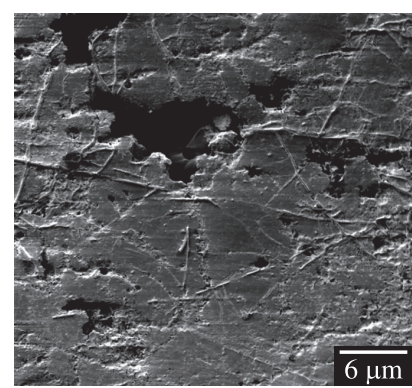

(e)

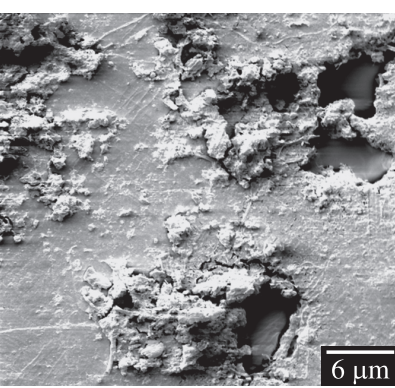

(f)

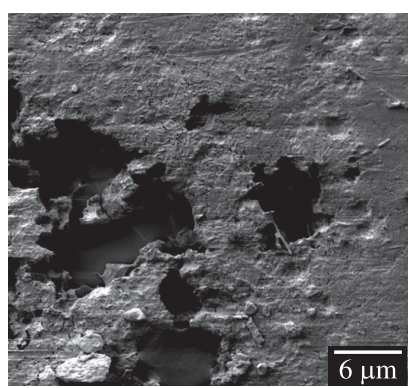

(g)

Figura 5. MEV de filmes de PCL: a) original; b) solo 30 dias; c) solo 45 dias; d) solo 60 dias; e) solo + chorume 30 dias; f) solo + chorume 45 dias e g) solo + chorume 60 dias. 


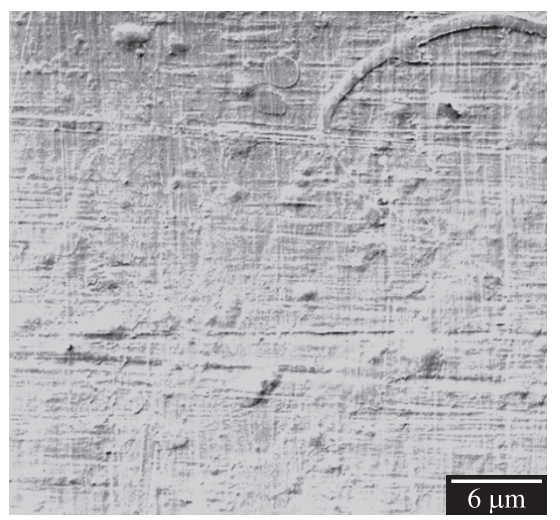

(a)

Figura 6. MEV de filmes de PP: a) original; b) solo e c) solo + chorume.

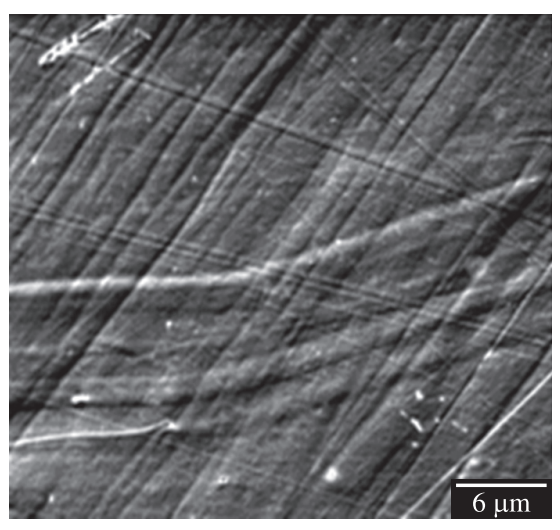

(a)

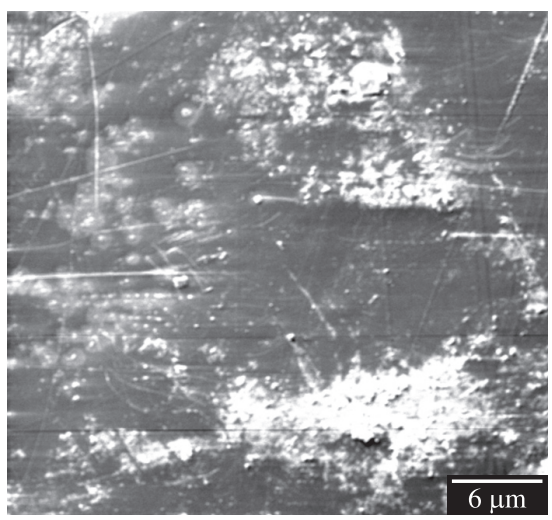

(b)

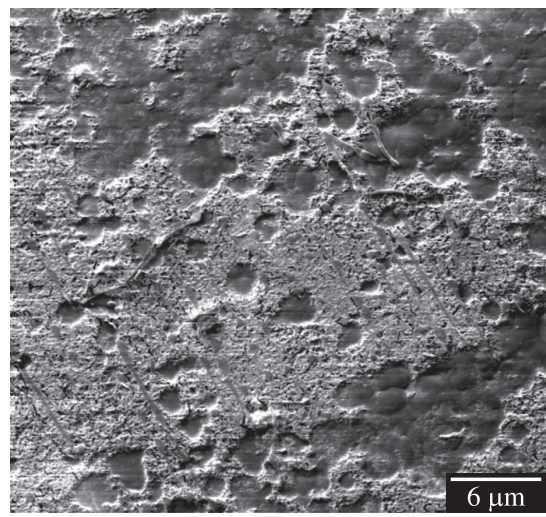

(b)

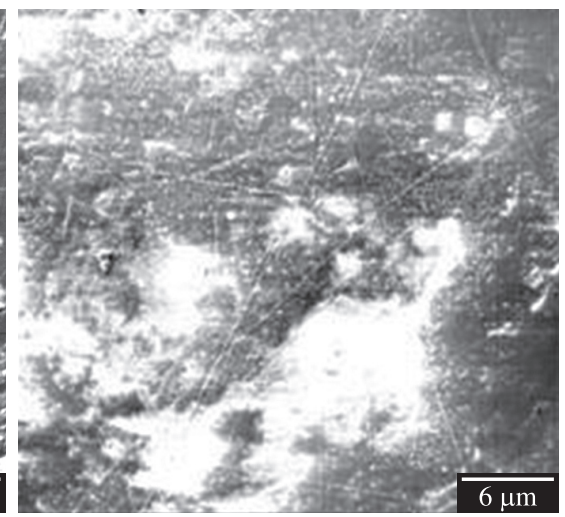

(c)

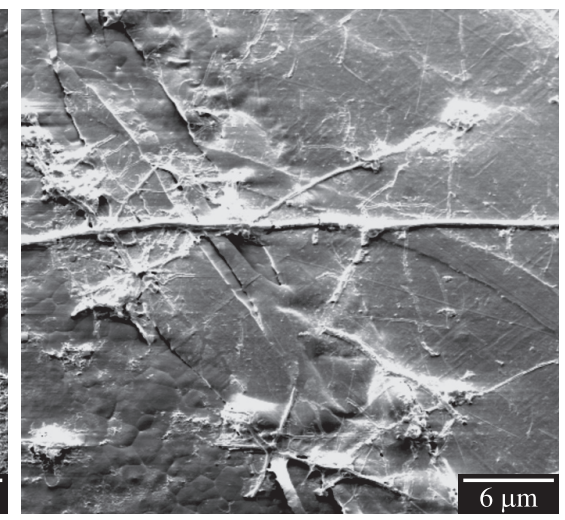

(c)

Figura 7. MEV de filmes de PP/PCL: a) original; b) solo e c) solo + chorume.

A biodegradação pode ocorrer preferencialmente na fase onde se encontra o PCL, ou na interfase dos dois polímeros, assim como observado por Gonçalves et al. ${ }^{[7]}$, em blendas de PP com PHBV.

\section{Conclusões}

Filmes de PCL são biodegradados em grande extensão por microrganismos do solo e do solo com chorume.

A adição de chorume ao solo inibe a biodegradação do PCL devido à modificação do sistema microbiano presente no solo e adição de diferentes microrganismos

A erosão na blenda é menos intensa devido às presença do PP

A heterogeneidade da blenda de PP/PCL limita o processo da biodegradação que, neste caso, ocorre nas interfases de PP e PCL.

\section{Agradecimentos}

Os autores agradecem à FAPESP pela bolsa de doutorado (Processo no. 04/14381-7).

\section{Referências Bibliográficas}

1. Lucas, N.; Bienaime, C.; Belloy, C.; Queneudec, M.; Silvestre, F. \& NavaSaucedo, J. E. -Chemosphere, 73, p. 429 (2008).

2. Shah, A. A.; Hasan, F.; Hameed, A. \& Ahmed, S. - Biotechnol. Adv., 26, p.246 (2008).

3. Peña, J.; Corrales, T.; Izquierdo-Barba, I.; Doadrio, A. L. \& Vallet-Regi, M. Polym. Degrad. Stabil., 91, p.1424 (2006).

4. Elzein, T.; Nasser-Eddine, M.; Delaite, C.; Bistac, S. \& Dumas, P. J. - Colloid Interface Sci., 273, p.381 (2004).

5. Amass, W. Amass, A. \& Tighe, B. - Polym. Intern., 47, p.89 (1998).

6. Manrich, S. - "Processamento de Termoplásticos: rosca única, extrusão e matrizes, injeção e moldes”, Artliber, São Paulo (2005).
7. Gonçalves, S. P. C.; Chinaglia, D. L. \& Martins-Franchetti, S. M. J. - Polym Environ., 17, p.280 (2009).

8. Tjong, S. C.; Xu, Y.; Meng, Y. Z. - Polymer, 40, p.3703 (1999).

9. Companhia de Tecnologia e Saneamento Ambiental - CETESB. - "Solos Determinação biodegradação de resíduos - Método respirométrico de Bartha", São Paulo (1990).

10. Campos, A.; Martins-Franchetti, S. M.; Marconato, J. C.; Agnelli, J. A. M. \& Monteiro, M. R. - Res. J. Biotech., 2 (2007).

11. Raij, B.; Andrade, J. C.; Cantarella, H. \& Quaggio, J. A. - "Análise química para avaliação da fertilidade de solos”, Instituto Agronômico (2001).

12. Lopes Filho, L.; Silva, W. T. L.; Milori, D. M. B. P. \& Simões, M. L. "Monitoramento químico e físico do processo de compostagem de diferentes resíduos orgânicos”, Embrapa, São Carlos ( 2005).

13. Associação Brasileira de Normas Técnicas. - "Resíduos em solo - Determinação da biodegradação pelo método respirométrico. Norma NBR 14283”, São Paulo (1999).

14. Darwis, D.; Mitomo, H.; Enjoji, T.; Yoshii, F. \& Makuuchi, K. - Polym. Degrad. Stabil., 62, p.259 (1998).

15. Kesel, C.; Vander Wauven, C. \& David, C. - Polym. Degrad. Stabil., 55, p.107 (1999).

16. Otaguro, H.; Artel, W. H.; Parra, D. F.; Cardoso, E. C. L.; Lima, L. F. C. P. \& Lugão, A. B. - Polímeros, 14, 2 (2004).

17. ASTM. - "ASTM D-5338-98: Standard Test Method for Determining Aerobic Biodegradation of Plastic Materials under Controlled Composting Conditions" (1998).

18. Arkatkar, A.; Arutchelvi, J.; Bhaduri, S.; Uppara, P. V. \& Doble, M. - Intern. Biodet. Biodegrad., 63, p.106 (2009).

19. Cacciari, I.; Quatrini, P.; Zirletta, G.; Mincione, E.; Vinciguerra, V.; Lupattelli, P. \& Giovannozzi Sermanni, G. - Appl. Environ. Microbiol., 59, p. 3695 (1993).

20. Chun, Y. S.; Han, M.; Park, J. \& Kim, W. N. - Korea-Australia Rheology J., 12, p.101 (2000).

Enviado: 24/10/09 Reenviado: 23/02/10

Aceito: 03/05/10

DOI: $10.1590 /$ S0104-14282010005000039 